This paper is dedicated to the $60^{\text {th }}$ anniversary of the foundation

of Institute of Physiology, Czechoslovak Academy of Sciences, Prague

\title{
Nifedipine-Sensitive Blood Pressure Component in Hypertensive Models Characterized by High Activity of Either Sympathetic Nervous System or Renin-Angiotensin System
}

\author{
J. ZICHA ${ }^{1}$, Z. DOBEŠOVÁ ${ }^{1}$, M. BEHULIAK ${ }^{1}$, M. PINTÉROVÁ ${ }^{1}$, J. KUNEŠ ${ }^{1}$, \\ I. VANĚČKOVÁ ${ }^{1}$
}

${ }^{1}$ Department of Experimental Hypertension, Institute of Physiology, Academy of Sciences of the Czech Republic, Prague, Czech Republic

Received December 9, 2013

Accepted January 3, 2014

On-line January 8, 2014

\section{Summary}

High blood pressure (BP) of spontaneously hypertensive rats (SHR) is maintained by enhanced activity of sympathetic nervous system (SNS), whereas that of Ren-2 transgenic rats (Ren-2 TGR) by increased activity of renin-angiotensin system (RAS). However, both types of hypertension are effectively attenuated by chronic blockade of L-type voltage-dependent calcium channel (L-VDCC). The aim of our study was to evaluate whether the magnitude of BP response elicited by acute nifedipine administration is proportional to the alterations of particular vasoactive systems (SNS, RAS, NO) known to modulate L-VDCC activity. We therefore studied these relationships not only in SHR, in which mean arterial pressure was modified in a wide range of $100-210 \mathrm{~mm} \mathrm{Hg}$ by chronic antihypertensive treatment (captopril or hydralazine) or its withdrawal, but also in rats with augmented RAS activity such as homozygous Ren-2 TGR, pertussis toxintreated SHR or L-NAME-treated SHR. In all studied groups the magnitude of $\mathrm{BP}$ response to nifedipine was proportional to actual BP level and it closely correlated with BP changes induced by acute combined blockade of RAS and SNS. BP response to nifedipine is also closely related to the degree of relative NO deficiency. This was true for both SNS- and RAS-dependent forms of genetic hypertension, suggesting common mechanisms responsible for enhanced L-VDCC opening and/or their upregulation in hypertensive animals. In conclusions, BP response to nifedipine is proportional to the vasoconstrictor activity exerted by both SNS and RAS, indicating a key importance of these two pressor systems for actual L-VDCC opening necessary for BP maintenance.

\section{Key words}

L-type voltage-dependent $\mathrm{Ca}^{2+}$ channels - Sympathetic nervous system • Renin-angiotensin system • Nitric oxide • Genetic hypertension

\section{Corresponding author}

Josef Zicha, Institute of Physiology AS CR, v.v.i., Videnska 1083, 14220 Prague 4, Czech Republic. Fax +420 24106 2488. E-mail: zicha@biomed.cas.cz

\section{Introduction}

Genetic hypertension in spontaneously hypertensive rats (SHR) is characterized by sympathetic hyperactivity (Head 1989, De Champlain 1990, Pintérová et al. 2011) and by augmented $\mathrm{Ca}^{2+}$ influx through L-type voltage-dependent $\mathrm{Ca}^{2+}$ channels ( $\mathrm{Ca}_{\mathrm{V}} 1.2$, L-VDCC) susceptible to the inhibition by nifedipine (Hermsmeyer 1991, Ohya et al. 1998, Cox and Rusch 2002, Sonkusare et al. 2006). Paulis et al. (2007) reported that the tonic phase of NE-induced contraction of isolated arteries, which is augmented in SHR, can be attenuated by calcium channel blocker nifedipine. This is in line with the fact that L-VDCC in vascular smooth muscle are activated by norepinephrine (NE) (Nelson et al. 1988). 
Using conscious rats we have demonstrated that a great part of sympathetic vasoconstriction is susceptible to the inhibition by nifedipine (Paulis et al. 2007). Moreover, nifedipine pretreatment of conscious rats attenuated their BP response to NE by shifting their NE dose-response curves to the right (Pintérová et al. 2010). Although the above findings support the importance of sympathetic nervous system (SNS) for the participation of L-VDCC in BP control, the alterations in $\beta$-adrenergic or NO-dependent vasodilatation might also contribute to the enhanced $\mathrm{Ca}^{2+}$ influx in hypertension because L-VDCC can be closed by elevated levels of cyclic nucleotides (both cAMP and cGMP) (Ishikawa et al. 1993, Orlov et al. 1996, Liu et al. 1997, Lewis et al. 2005, Pintérová et al. 2009).

In contrast to a prominent role of sympathetic hyperactivity in SHR, high BP of homozygous Ren-2 transgenic rats is maintained by the enhanced RAS activity accompanied by almost unchanged contribution of SNS (Vaněčková et al. 2012). It should be noted that hypertension in these transgenic rats can be attenuated not only by different chronic RAS interventions (Bader $e t$ al. 1992, Böhm et al. 1998) but also by chronic administration of various L-VDCC blockers (Bishop et al. 2000, Witte et al. 2001, Park et al. 2002). The BP lowering effects of acute nitrendipine administration to Ren-2 TGR were comparable to those of captopril (HirthDietrich et al. 1994).

The acute administration of L-VDCC blockers (such as verapamil, diltiazem or nifedipine) caused the exaggerated hypotensive response in hypertensive rats (SHR, Dahl salt-sensitive rats) compared to normotensive controls (Takata and Hutchinson 1983, Narita et al. 1983, Sharma et al. 1984). Kuneš et al. (2004) reported the enhanced BP fall following acute nifedipine administration to rats with three different forms of experimental hypertension - genetic (SHR), salt-dependent (Dahl rats) and NO-deficient (chronic L-NAME treatment), all of them being characterized by increased SNS participation (Zicha et al. 2001, Dobešová et al. 2002, Pecháńová et al. 2004, Hojná et al. 2007). In all above mentioned types of hypertension the nifedipineinduced BP reduction was always proportional to basal BP level (Kuneš et al. 2004, Paulis et al. 2007). Moreover, chronic blockade of renin-angiotensin system (RAS) by captopril, which effectively lowered BP of SHR through a considerable attenuation of sympathetic vasoconstriction (Berecek et al. 1987), was accompanied by a reduction of their BP response to nifedipine administration (Paulis et al. 2007). Finally, chronic administration of L-VDCC blockers not only lowered BP of SHR but also attenuated the contractile response of their arteries to depolarization and/or $\alpha$-adrenergic stimulation (Kazda et al. 1985, Godfraind et al. 1991). The reported upregulation of L-VDCC (increased expression of the pore-forming $\alpha_{1 C}$ subunit) in SHR (Pratt et al. 2002) was ascribed to the elevation of intravascular pressure (Pesic et al. 2004). The underlying mechanisms seem to involve membrane depolarization (Pesic et al. 2004, Sonkusare et al. 2006) but the effects of an increased levels of angiotensin II (Ang II) (Wang et al. 2008) and/or sympathetic hyperactivity (Paulis et al. 2007) cannot be completely ruled out.

The aim of our study was to test whether the magnitude of BP response elicited by acute nifedipine administration is dependent on the actual activity of particular vasoactive systems known to regulate blood pressure by modulation of L-VDCC opening (SNS, NO, RAS) or whether it simply reflects chronic BP level known to be responsible for the upregulation of L-VDCC. To achieve this goal we studied young SHR developing high BP and adult SHR with established hypertension in which mean arterial pressure (MAP) was modified in the range of $100-210 \mathrm{~mm} \mathrm{Hg}$ by chronic pharmacological interventions (captopril or hydralazine for six weeks) and/or by the long-term withdrawal of these drugs for further four weeks. We also examined two age groups of homozygous Ren-2 TGR with Ang II-dependent hypertension and two particular SHR groups in which sympathetic vasoconstriction was partially replaced by Ang II-dependent vasoconstriction, i.e. pertussis toxin (PTX)-treated SHR with a rather low BP (Pintérová et al. 2010) and L-NAME-treated SHR with malignant hypertension (Zicha et al. 2009).

\section{Methods}

Animals

The experiments on genetic hypertension characterized by enhanced sympathetic activity started either in young prehypertensive (4-week-old) or in adult (24-week-old) male SHR. We always compared untreated animals with those treated by angiotensin-converting enzyme inhibitor captopril (100 $\mathrm{mg} / \mathrm{kg} /$ day $)$ or vasodilator hydralazine $(12 \mathrm{mg} / \mathrm{kg} /$ day $)$ for 6 weeks. In the additional SHR groups the antihypertensive treatments were withdrawn for 4 weeks. Age-matched Wistar-Kyoto (WKY) rats served as normotensive 
controls. Table 1 shows the scheme of experiments and the number of rats in particular experimental groups used for the evaluation of either the participation of L-VDCC in BP regulation (Nifedipine Protocol) or the balance of principal vasoconstrictor and vasodilator systems (Vasoactive Balance Protocol).

Furthermore, we have studied some Ang II-dependent forms of experimental hypertension. We have therefore included two groups of homozygous Ren-2 transgenic male rats aged 7 and 11 weeks with angiotensin II-dependent hypertension and their agematched normotensive Hannover-Sprague Dawley (HanSD) controls (Table 1). We have also examined two different groups of SHR (PTX-treated or L-NAMEtreated animals) that are characterized by a high contribution of pressor effects of RAS to BP maintenance (Table 1). Twenty-six male SHR rats aged 12 weeks were randomly allocated into two experimental groups: untreated and PTX-treated animals. PTX, which is a toxin capable to inactivate $G_{i}$ proteins, was injected $(10 \mu \mathrm{g} / \mathrm{kg}$ b.w.) to the right jugular vein $48 \mathrm{~h}$ prior to the experiments. Furthermore, 30 male SHR rats aged 13 weeks were either untreated or subjected to chronic L-NAME treatment ( $25 \mathrm{mg} / \mathrm{kg} /$ day in drinking fluid) for 4 weeks.

All animals were obtained from the colonies held in the Institute of Physiology AS CR, Prague. Rats were housed under standard laboratory conditions (temperature $23 \pm 1{ }^{\circ} \mathrm{C}, 12$-h light-dark), were fed pelleted ST-1 diet $(1 \% \mathrm{NaCl})$ and drank tap water ad libitum. All procedures and experimental protocols, which were approved by the Ethical Committee of the Institute of Physiology AS CR, conform to the European Convention on Animal Protection and Guidelines on Research Animal Use.

\section{Blood pressure measurement}

One day before BP determination, polyethylene catheters were inserted into left carotid artery (PE 50 for BP measurement) and left jugular vein (PE 10 for drug injection) and exteriorized in the interscapular region. BP was recorded in conscious animals after 24-h recovery using PowerLab system (ADInstruments Ltd, Bella Vista, Australia). Four animals were recorded simultaneously. To eliminate circadian BP variations, BP measurements were always done between 08:00 and 11:30 AM. Since BP effects of principal vasoactive systems (RAS, SNS and NO) are substantially modified by the acute L-VDCC blockade (Paulis et al. 2007, Pintérová et al. 2009), we had to use separate subgroups of animals for the investigation on the role of either L-VDCC (Nifedipine Protocol) or vasoactive systems (Vasoactive Balance Protocol).

Acute blockade of L-type voltage-dependent $\mathrm{Ca}^{2+}$ channels (Nifedipine Protocol)

After monitoring basal BP for $30 \mathrm{~min}$, increasing doses of nifedipine $(0.05,0.1,0.2$ and $0.4 \mathrm{mg} / \mathrm{kg} \mathrm{b.w.)}$ were injected intravenously in 10-min intervals (for typical dose-response curves see ref. 8). BP values, that were stabilized after the cumulative nifedipine dose $(0.75 \mathrm{mg} / \mathrm{kg} \quad$ b.w.), were used for calculation of nifedipine-induced BP reduction (Zicha et al. 2011).

Sequential blockade of vasoactive Systems (Vasoactive Balance Protocol)

Basal BP was monitored in conscious animals for $30 \mathrm{~min}$. Thereafter, a consecutive blockade of RAS, SNS and NO synthase (NOS) was performed as described previously (Zicha et al. 2001, Kuneš et al. 2002, Zicha et al. 2006). Firstly, captopril (10 mg/kg b.w.) was injected to block angiotensin-converting enzyme. Ten minutes later, ganglionic blockade induced by pentolinium ( $5 \mathrm{mg} / \mathrm{kg}$ b.w.) prevented sympathetic vasoconstriction, eliciting thus a rapid BP fall. When BP was stabilized for about $5 \mathrm{~min}$, NO synthase (NOS) was inhibited by $\mathrm{N}^{\omega}{ }^{\omega}$-nitro-L-arginine methyl ester (L-NAME, $30 \mathrm{mg} / \mathrm{kg}$ b.w.) and BP increase was monitored for $20 \mathrm{~min}$.

\section{Drugs}

All drugs were purchased at Sigma (St. Louis, MO, USA). Nifedipine was dissolved in $50 \%$ ethanol $(1 \mathrm{mg} / \mathrm{ml})$ and injected intravenously in volumes up to $0.4 \mathrm{ml} / \mathrm{kg}$ b.w.. This vehicle had no significant lasting BP effects. All other drugs (captopril, pentolinium, L-NAME) were dissolved in saline, were used in doses eliciting maximal BP effects and were given as an intravenous bolus injection ( $1 \mathrm{ml} / \mathrm{kg}$ b.w.).

\section{Statistics}

Results were expressed as means \pm SEM. Data were evaluated by one-way analysis of variance with post-hoc Least Significant Difference test. We also performed correlation analysis of the relationships between basal MAP and particular BP components (using both absolute values and relative values expressed in terms of basal $\mathrm{BP}$ ). $\mathrm{P}<0.05$ was taken as statistically significant. 
Table 1. The list of the experimental groups indicating the age of animals at the onset of the experiment and the duration of the experiments. Blood pressure was always measured at the end of the experiment.

\begin{tabular}{|c|c|c|c|c|}
\hline Group & $\begin{array}{l}\text { Age at onset } \\
\text { (weeks) }\end{array}$ & $\begin{array}{c}\text { Duration } \\
\text { (weeks) }\end{array}$ & n1 (Nifedipine) & n2 (Balance) \\
\hline
\end{tabular}

Spontaneous hypertension and its modifications by antihypertensive interventions

\begin{tabular}{|c|c|c|c|c|}
\hline \multicolumn{5}{|l|}{ YOUNG } \\
\hline WKY untreated & 4 & 6 & 9 & 10 \\
\hline WKY untreated & 4 & 10 & 9 & 10 \\
\hline SHR untreated & 4 & 6 & 8 & 10 \\
\hline SHR untreated & 4 & 10 & 9 & 8 \\
\hline SHR captopril & 4 & 6 & 10 & 13 \\
\hline SHR captopril withdrawal & 4 & 10 & 8 & 9 \\
\hline SHR hydralazine & 4 & 6 & 12 & 12 \\
\hline SHR hydralazine withdrawal & 4 & 10 & 6 & 6 \\
\hline \multicolumn{5}{|l|}{ ADULT } \\
\hline WKY untreated & 24 & 6 & 6 & 9 \\
\hline WKY untreated & 24 & 10 & 5 & 9 \\
\hline SHR untreated & 24 & 6 & 8 & 7 \\
\hline SHR untreated & 24 & 10 & 9 & 7 \\
\hline SHR captopril & 24 & 6 & 7 & 7 \\
\hline SHR captopril withdrawal & 24 & 10 & 9 & 7 \\
\hline SHR hydralazine & 24 & 6 & 5 & 9 \\
\hline SHR hydralazine withdrawal & 24 & 10 & 7 & 7 \\
\hline
\end{tabular}

Groups with enhanced angiotensin II contribution to BP maintenance (and their controls)

\begin{tabular}{lcccc} 
YOUNG & & & & \\
HanSD & 4 & 3 & 6 & 6 \\
Ren-2 TGR & 4 & 3 & 8 & 10 \\
ADULT & & & 6 & 9 \\
HanSD & 4 & 7 & 6 & 6 \\
Ren-2 TGR & 4 & 7 & 6 & 8 \\
Gi protein inactivation & & & & \\
Untreated SHR & 12 & 2 days & 9 & 6 \\
PTX-treated SHR & 12 & & 8 & 7 \\
Chronic NO synthase inhibition & & 4 & & \\
Untreated SHR & 13 & 4 & & \\
L-NAME-treated SHR & 13 & & & \\
\hline
\end{tabular}

WKY - Wistar-Kyoto rats, SHR - spontaneously hypertensive rats, HanSD - Hannover Sprague Dawley rats, Ren-2 TGR - transgenic rats with mouse renin gene, PTX - pertussis toxin 


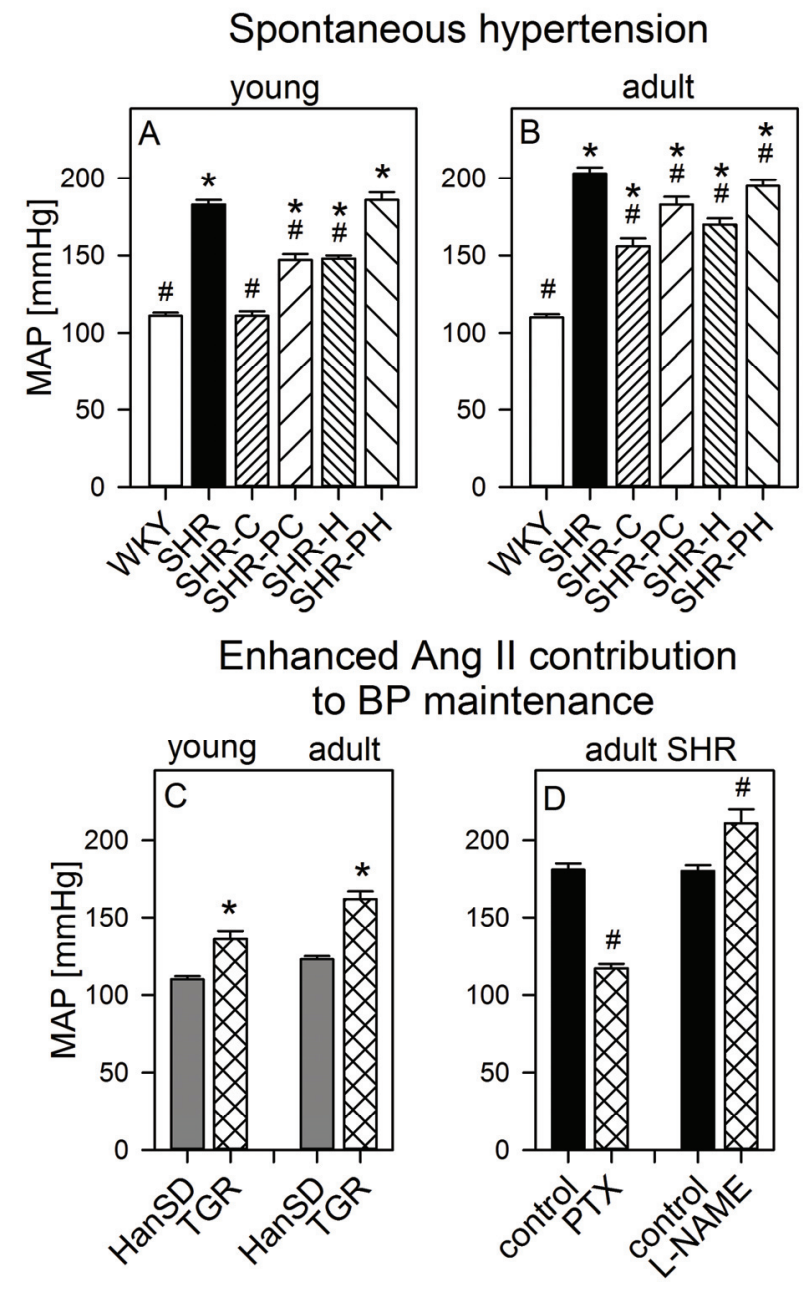

Fig. 1. Basal BP values. Mean arterial pressure (MAP) was recorded in conscious spontaneously hypertensive rats influenced by various antihypertensive interventions (upper panels) and in rats with enhanced Ang II contribution to BP maintenance (lower panels). Untreated WKY and SHR as well as captopril-treated SHR (SHR-C) and hydralazine-treated SHR (SHR-H) measured during the active drug treatment or 4 weeks after drug withdrawal (SHR-PC and SHR-PH, respectively) are shown in panel A (young animals) and panel B (adult animals). Ren-2 transgenic (TGR) rats and their normotensive controls (HanSD) are shown in panel C, whereas panel D depicts PTX-treated SHR and L-NAME-treated SHR with their age-matched untreated SHR controls. Data are means \pm SEM. Symbols denote significant differences $(P<0.05)$ : * vs. untreated WKY, ${ }^{\#}$ vs. untreated SHR.

\section{Results}

Basal blood pressure and BP response to nifedipine (Nifedipine Protocol)

Figures $1 \mathrm{~A}$ and $1 \mathrm{~B}$ show that basal MAP of both young (10-week-old) and adult (30-week-old) SHR was substantially elevated due to the augmentation of the nifedipine-sensitive BP component (Figs 2A and 2B). The active antihypertensive treatment with captopril for

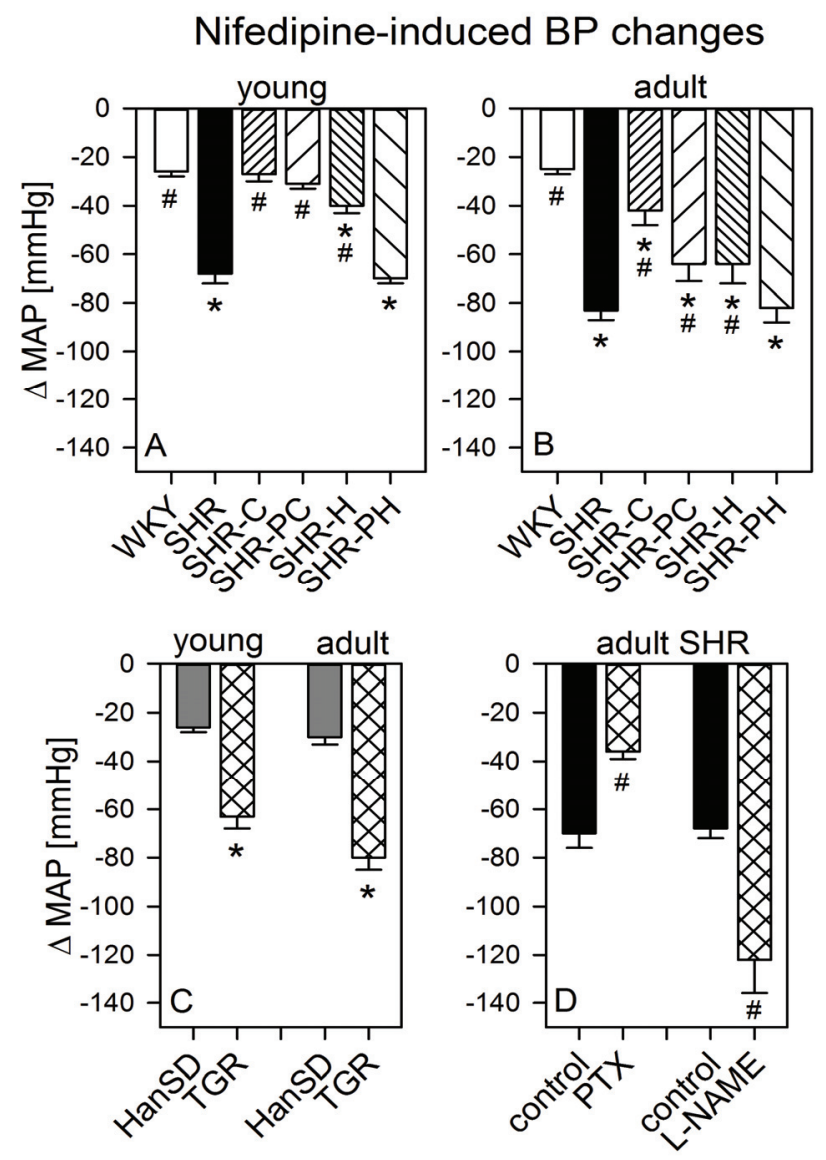

Fig. 2. Nifedipine-induced BP changes. MAP changes induced by acute L-VDCC inhibition by nifedipine in spontaneously hypertensive rats influenced by various antihypertensive interventions (upper panels) and in rats with enhanced Ang II contribution to BP maintenance (lower panels). For other legend see Figure 1.

6 weeks entirely prevented hypertension development in young prehypertensive SHR but it lowered MAP only partly in adult SHR with established hypertension. The antihypertensive effects of hydralazine were less pronounced than those of captopril in young SHR but this was not the case in adult animals. The withdrawal of antihypertensive drugs for 4 weeks caused a significant MAP elevation in all groups, but basal MAP remained relatively lower in young SHR withdrawn from captopril therapy (Fig. 1A). BP responses to acute nifedipine administration were augmented in both age groups of untreated SHR compared to normotensive controls and they were attenuated by antihypertensive treatments so that nifedipine-induced MAP fall was inversely related to basal MAP values in all groups (Figs 2A and 2B).

The elevated MAP in homozygous Ren-2 TGR (Fig. 1C) was also accompanied by the enhanced nifedipine-sensitive BP component (Fig. 2C). Similarly, 
the major MAP reduction in PTX-treated SHR was associated with the appropriate attenuation of nifedipineinduced MAP change, whereas the considerable MAP increase in L-NAME treated SHR was paralleled by the augmentation of nifedipine-sensitive BP component (Figs 1D and 2D).

Balance of vasoconstrictor and vasodilator systems (Vasoactive Balance Protocol)

Vasoactive balance had to be studied in separate subgroups of animals because L-VDCC blockade by nifedipine would interfere with the evaluation of both sympathetic vasoconstriction (Paulis et al. 2007) and NO-dependent vasodilatation (Pintérová et al. 2010). Nevertheless, the average values of basal MAP in particular experimental subgroups subjected to this protocol were almost identical as those found in subgroups used for Nifedipine Protocol.
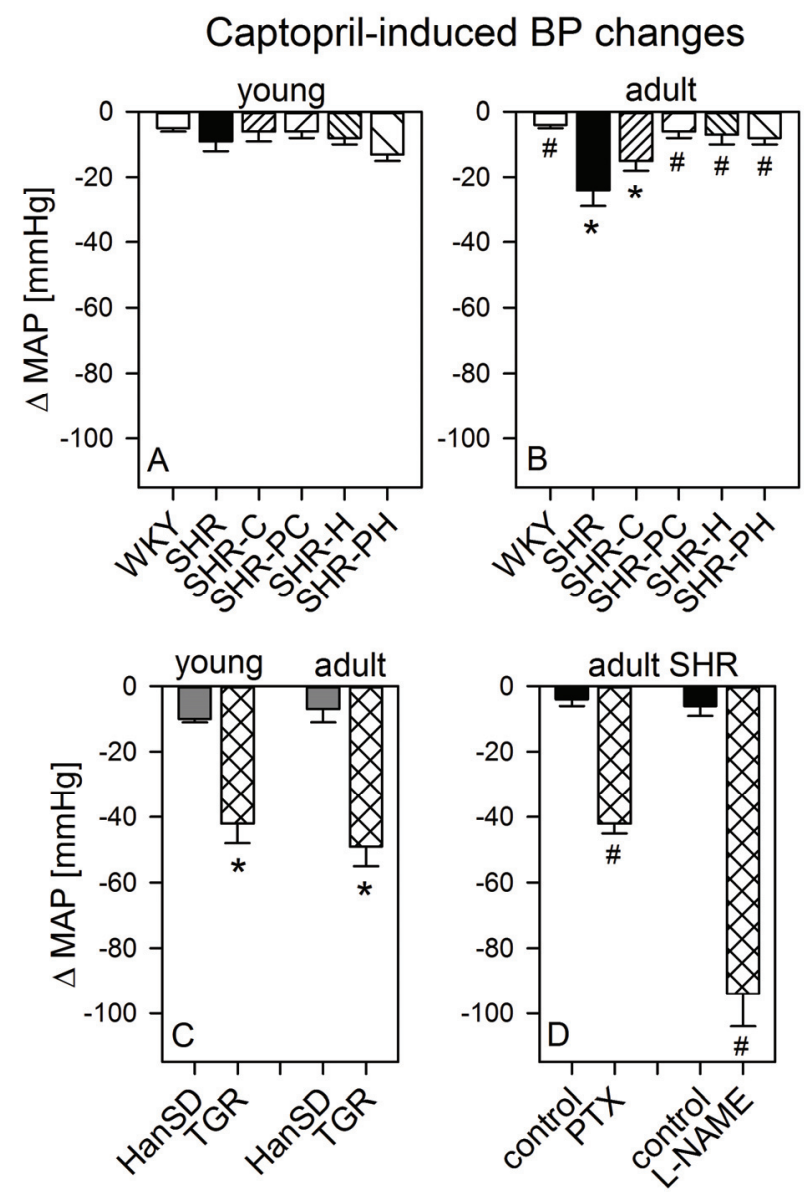

Fig. 3. Captopril-induced BP changes. MAP changes induced by acute inhibition of renin-angiotensin system by captopril in conscious spontaneously hypertensive rats influenced by various antihypertensive interventions (upper panels) and in rats with enhanced Ang II contribution to BP maintenance (lower panels). For other legend see Figure 1.

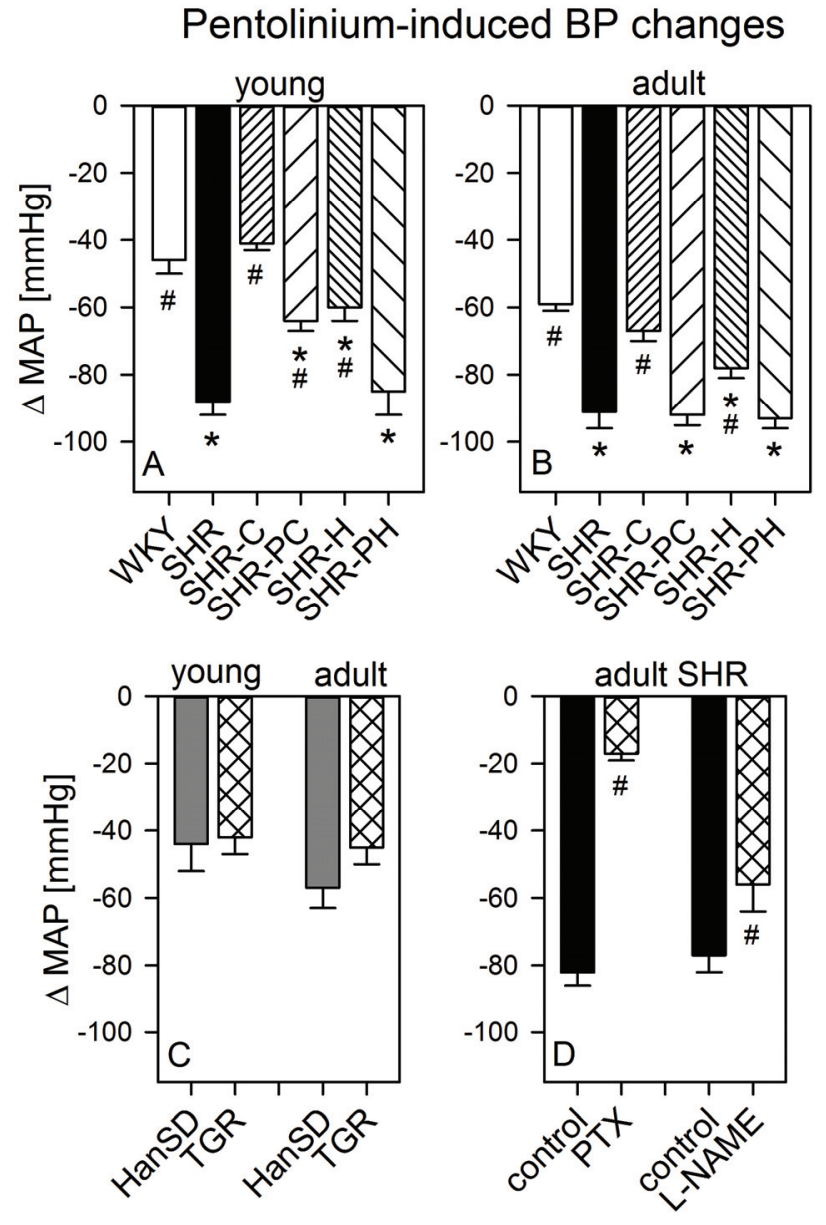

Fig. 4. Pentolinium-induced $B P$ changes. MAP changes induced by acute inhibition of sympathetic nervous system by pentolinium in conscious spontaneously hypertensive rats influenced by various antihypertensive interventions (upper panels) and in rats with enhanced Ang II contribution to BP maintenance (lower panels). For other legend see Figure 1.

In spontaneous hypertension characterized by sympathetic hyperactivity the contribution of Ang II-dependent vasoconstriction to BP maintenance was rather small in all groups (Figs 3A and 3B) except for untreated adult SHR and captopril-treated adult SHR in which the acute captopril injection induced MAP decrease by 24 and $15 \mathrm{~mm} \mathrm{Hg}$, respectively (Fig. 3B). On the contrary, sympathetic vasoconstriction was responsible not only for the greatest part of MAP elevation in untreated SHR but also for MAP changes elicited by both antihypertensive drugs and their withdrawal (Figs 4A and 4B). It should be pointed out that MAP changes induced by chronic RAS blockade were achieved entirely by the reduction of sympathetic vasoconstriction. It is also evident that the magnitudes of sympathetic BP component in particular experimental groups (Figs $4 \mathrm{~A}$ and $4 \mathrm{~B}$ ) were similar to those of nifedipine-sensitive BP component (Figs 2A and 2B). Surprisingly, no signs of NO deficiency 
were disclosed in either age group of untreated SHR because L-NAME-induced MAP rise in young SHR was similar to that in age-matched WKY rats and it was even significantly augmented in adult SHR with severe hypertension. Nevertheless, no major improvements of NO-dependent vasodilatation were observed in SHR subjected to antihypertensive treatments and there were no significant changes of NO-dependent vasodilatation after therapy withdrawal (Figs 5A and 5B). It is thus evident that in spontaneous hypertension the basal BP level is proportional to the sympathetic vasoconstriction, whereas this is not the case for Ang II-dependent vasoconstriction or NO-dependent vasodilatation.

\section{L-NAME-induced BP changes}
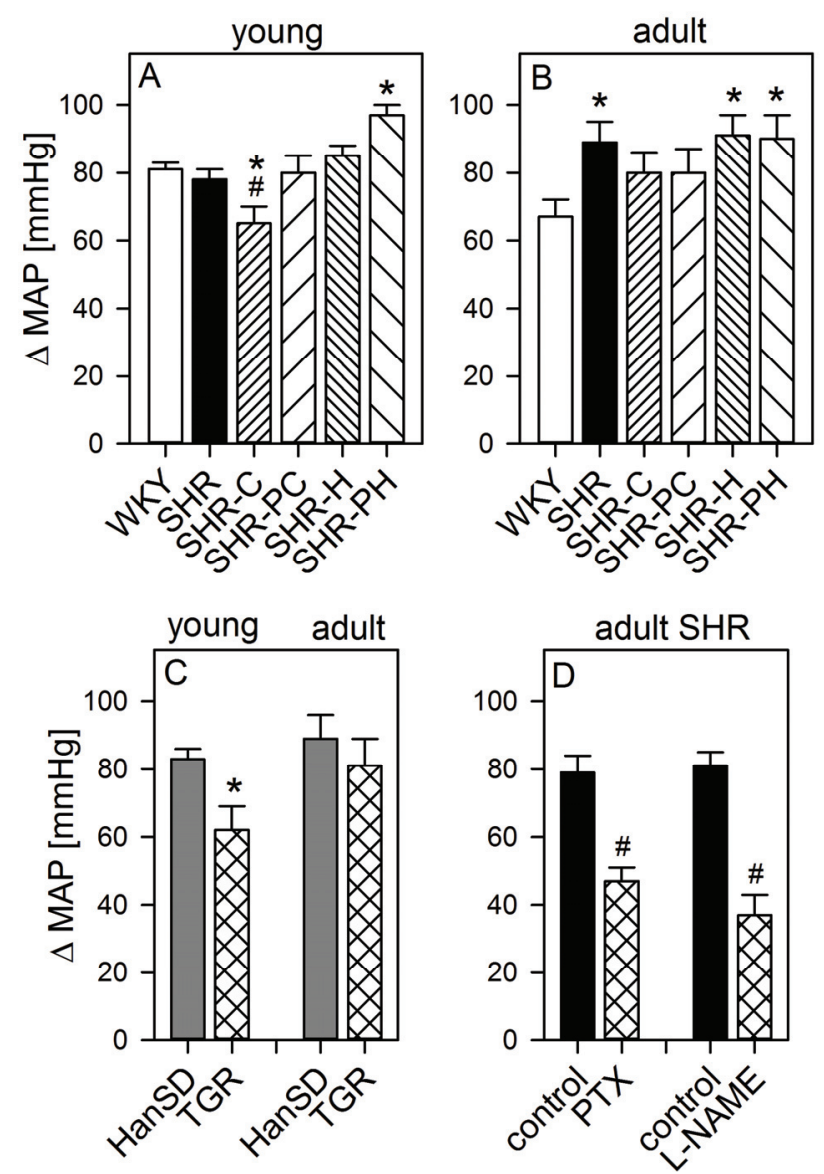

Fig. 5. L-NAME-induced BP changes. MAP changes induced by acute inhibition of NO synthase by L-NAME in conscious spontaneously hypertensive rats influenced by various antihypertensive interventions (upper panels) and in rats with enhanced Ang II contribution to BP maintenance (lower panels). For other legend see Figure 1.

Enhanced pressor role of endogenous Ang II was demonstrated not only in both age groups of homozygous Ren-2 TGR (Fig. 3C) but also in two experimental groups of SHR which were either subjected to in vivo PTX pretreatment (leading to the inactivation of inhibitory $G$ proteins) or chronically treated with L-NAME (causing severe NO deficiency) (Fig. 3D). Although MAP of homozygous Ren-2 TGR was elevated due to the augmentation of Ang II-dependent BP component, their sympathetic BP component was not significantly changed (Fig. 4C). In both age groups of Ren-2 TGR animals the nifedipine-sensitive MAP decrease (Fig. 2C) was greater than MAP reductions elicited by acute administration of either captopril or pentolinium to these animals (Figs 3C and $4 \mathrm{C})$.

A drastic reduction of pentolinium-induced MAP fall (sympathetic BP component) was observed in SHR studied 48 hours after PTX administration (Fig. 4D) and this change was accompanied by a multifold increase in captopril-induced MAP fall (Ang II-dependent BP component) (Fig. 3D). The overall transformation of the role of the above pressor systems in PTX-treated SHR led to a major MAP reduction, which was associated with a significant attenuation of MAP response to nifedipine (Fig. 2D). On the other hand, chronic L-NAME treatment of SHR caused a severe malignant hypertension that was largely dependent on augmented pressor effects of Ang II, whereas sympathetic vasoconstriction tended to be attenuated (Figs 3D and 4D). MAP fall induced by acute nifedipine injection in these severely hypertensive animals (Fig. 2D) clearly surpassed not only MAP response to pentolinium but also BP response to captopril (Figs 3D and 4D).

\section{Relationship of particular BP components to basal blood pressure}

In the whole population of rats with spontaneous hypertension characterized by enhanced sympathetic activity (groups shown in Fig. 1) there was a significant correlation of basal MAP with captopril-induced MAP changes but with a moderate slope (Fig. 6A). This relationship disappears when relative captopril-induced MAP changes are considered (Fig. 6B). In contrast, we have found a very strong correlation of basal MAP with pentolinium-induced MAP fall (reflecting the magnitude of sympathetic vasoconstriction) that was characterized by a much steeper slope of this relationship (Fig. 6C). This was accompanied by a moderate association of basal MAP with L-NAME-induced MAP rise (indicating the extent of NO-dependent vasodilatation) (Fig. 6E). It is evident that the slope of the regression line was steeper for sympathetic vasoconstriction than for NO-dependent vasodilatation, suggesting its incomplete compensatory activation. 

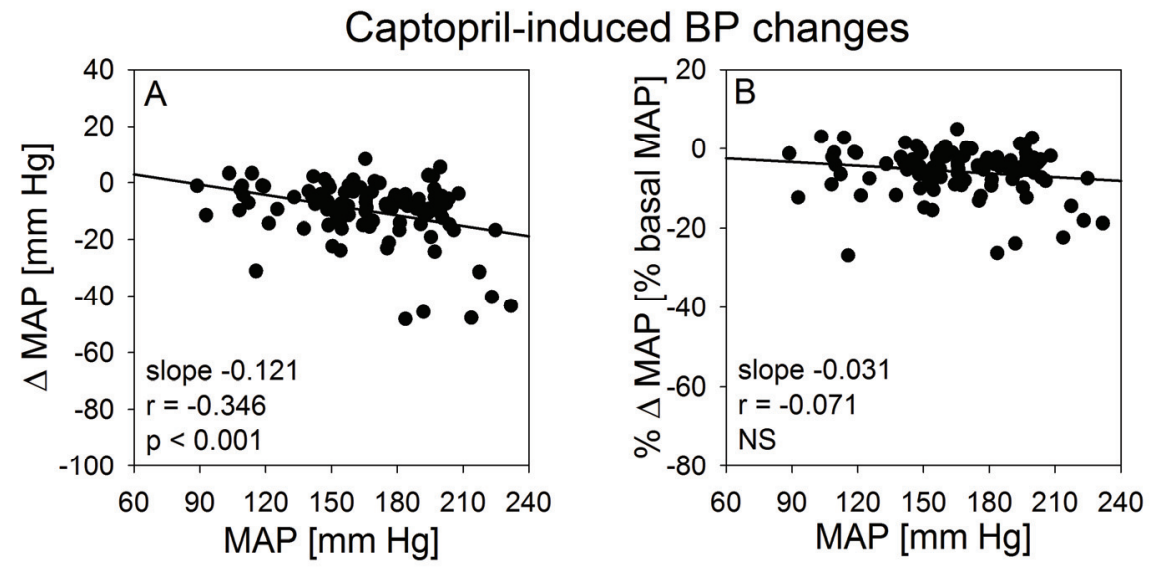

Fig. 6. The relationships of major vasoactive systems to basal $B P$. The correlations between basal MAP and pentolinium-induced MAP changes (upper panels), L-NAME-induced MAP changes (middle panels) and nifedipine-induced MAP changes (lower panels) expressed either as absolute changes (left panels) or as relative changes in terms of basal MAP (right panels) in the whole SHR population (except for groups with enhanced Ang II contribution to BP maintenance).
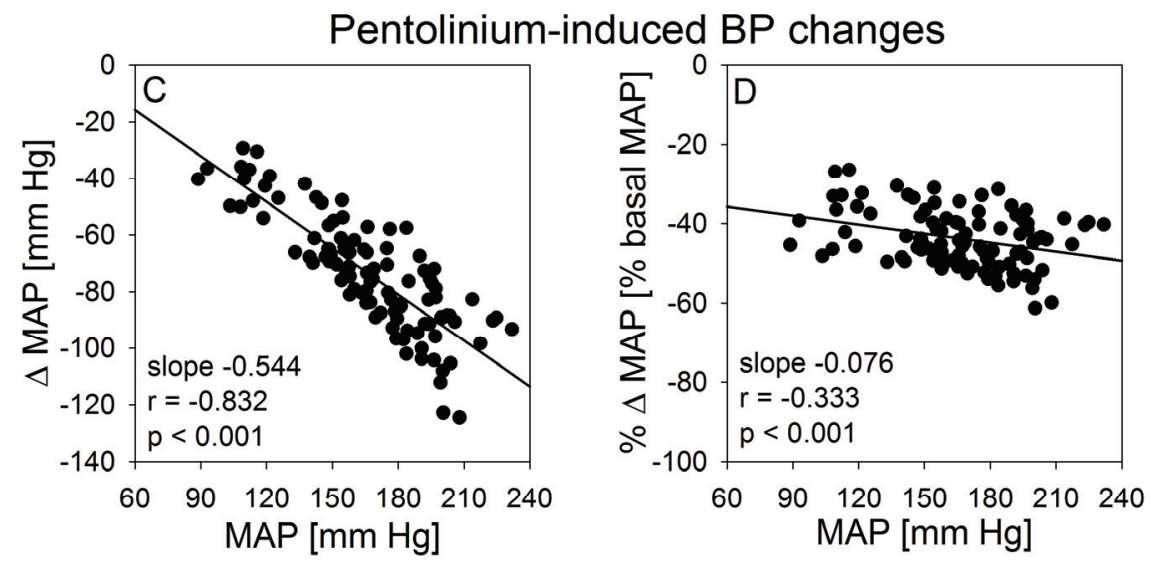

L-NAME-induced BP changes
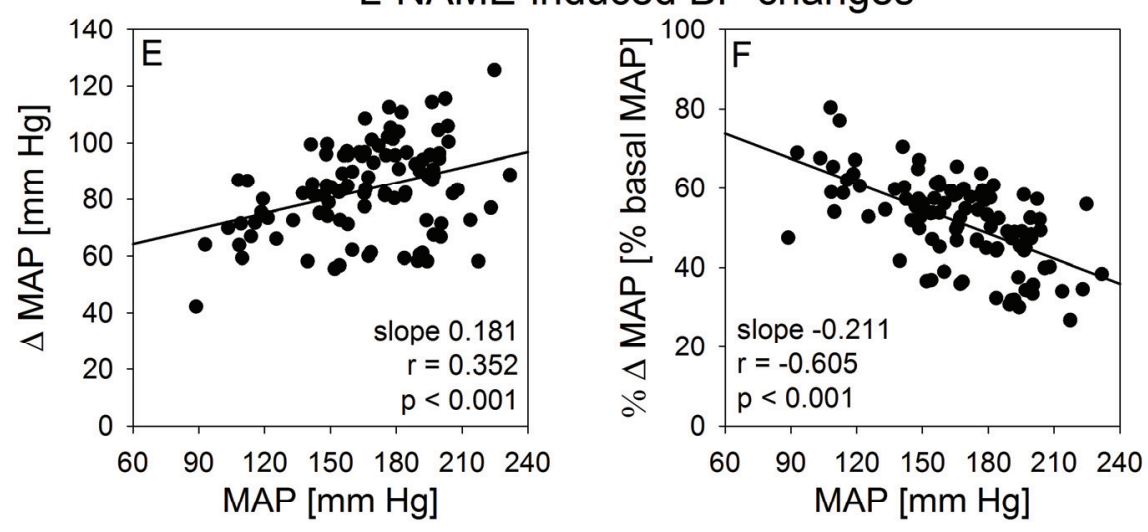

Nifedipine-induced BP changes
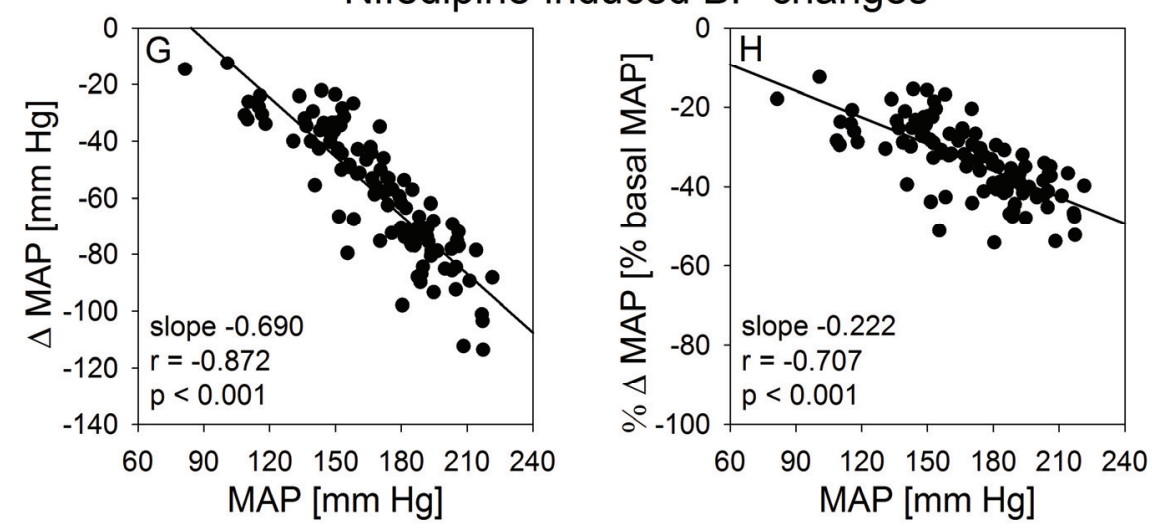
Furthermore, we also expressed pentolinium- or L-NAME-induced MAP changes as percentage of basal MAP to obtain relative contribution of these systems to BP maintenance. The significant correlation of basal MAP with relative pentolinium-induced MAP changes (Fig. 6D) confirmed that elevated basal MAP level of hypertensive rats was mainly due to the increased sympathetic hyperactivity. On the other hand, relative L-NAME-induced MAP changes were inversely related to basal MAP values (Fig. 6F), indicating a relative NO deficiency in hypertensive animals in which NO-dependent vasodilatation fails to counteract progressively increasing sympathetic vasoconstriction. It should be pointed out that in this combined SHR population we have observed a highly significant correlation between basal MAP and nifedipine-induced MAP changes (Fig. 6G). This relationship had a very steep slope, surpassing considerably the slope of the relationship between basal MAP and pentoliniuminduced MAP changes. Moreover, there was also a highly significant correlation of basal MAP with relative nifedipine-induced MAP changes, indicating that the contribution of this component of sympathetic vasoconstriction to BP maintenance rose markedly with increasing severity of hypertension (Fig. $6 \mathrm{H}$ ). Nifedipineinduced MAP changes also correlated significantly with basal MAP in separate sets of either young or adult SHR and WKY rats $(\mathrm{r}=-0.890, \mathrm{n}=71$ and $\mathrm{r}=-0.881, \mathrm{n}=56$, $\mathrm{p}<0.0001$ both).

When we analyzed the groups with enhanced Ang II contribution to BP maintenance, it was evident that basal MAP was proportional not only to captoprilinduced MAP fall but also to pentolinium-induced MAP reduction ( $\mathrm{r}=-0.729$ and $-0.622, \mathrm{n}=31, \mathrm{P}<0.001$ both). Of course, the slope of the relationship was steeper for Ang II-dependent than for sympathetic BP component (slope values -0.583 vs. -0.419 ). The relative L-NAMEinduced MAP changes were inversely related to basal MAP values $(\mathrm{r}=-0.453, \quad \mathrm{P}<0.02)$, confirming the importance of a relative NO deficiency even in these hypertensive animals. Both absolute and relative nifedipine-induced MAP changes closely correlated with basal MAP values of rats with enhanced Ang II contribution $(\mathrm{r}=-0.974, \mathrm{n}=22, \mathrm{P}<0.001$, slope -0.922$)$ and there was also a significant correlation of relative nifedipine-induced MAP changes with basal MAP values $(\mathrm{r}=-0.918, \mathrm{n}=22, \mathrm{P}<0.001)$.
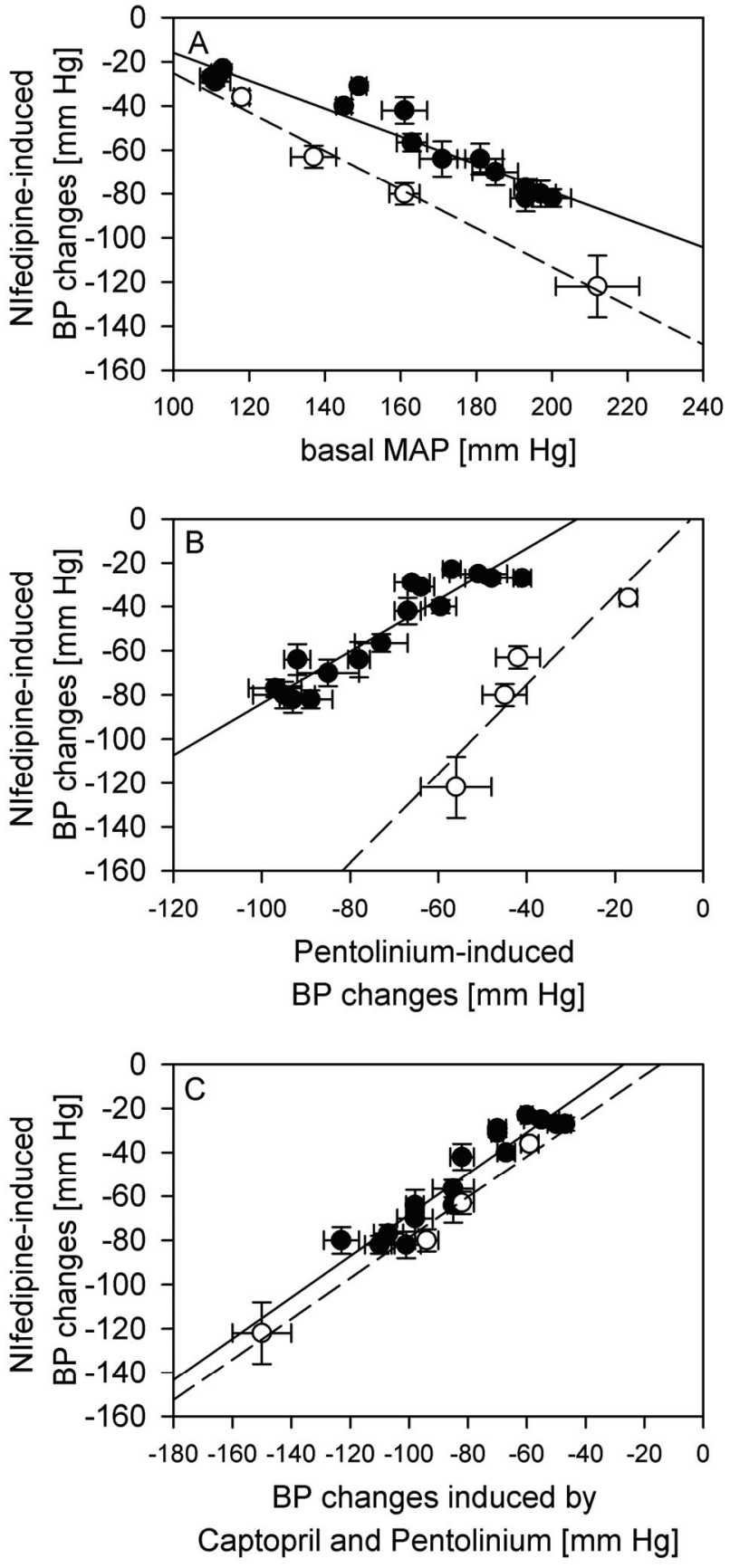

Fig. 7. The contribution of L-VDCC to BP maintenance and to particular BP components. The relationships of nifedipine-induced MAP changes to basal MAP (panel A), to pentolinium-induced MAP changes (panel B) and to the sum of captopril- and pentolinium-induced MAP changes (panel $\mathrm{C}$ ). The full regression lines were fitted to the full symbols representing average values \pm SEM obtained within the frame of Nifedipine and Vasoactive Balance Protocols in particular experimental SHR and WKY groups (first 16 groups shown in Table 1). The respective correlation coefficients were $r=-0.935,0.961$ and 0.943 for panels $A, B$ and $C$, respectively. Broken regression lines were fitted to four additional experimental groups with enhanced Ang II contribution to BP maintenance (open symbols). 
Relationships of nifedipine-induced BP changes to basal blood pressure and to the contribution of principal vasoconstrictor systems

In all groups studied the MAP responses to nifedipine were related to the actual level of basal MAP (Fig. 7A). However, the values of nifedipine-induced MAP decrease found in rats with enhanced contribution of Ang II to BP maintenance were slightly enhanced as compared to the regression line obtained in the first 16 groups of SHR and WKY rats listed in Table 1. Nifedipine-induced MAP changes in Ang II-dependent groups were always shifted to much greater values as could be expected on the basis of MAP changes induced by SNS blockade in those above mentioned 16 groups (Fig. 7B). However, in all examined groups the nifedipine-induced MAP reduction was exactly proportional to BP decrease elicited by the combined RAS and SNS blockade, i.e. the sum of captopril- and pentolinium-induced MAP changes (Fig. 7C). In the four experimental groups characterized by enhanced contribution of Ang II to BP maintenance we have observed that the nifedipine-induced MAP changes were proportional not only to MAP changes elicited by captopril but also to those induced by pentolinium ( $r=0.910$ and $0.926, p<0.05$ both). Interestingly, the augmentation of nifedipine-induced MAP reduction in both types of hypertension was also closely associated with the degree of relative NO deficiency (reflected by relative L-NAME-induced MAP changes) $(r=0.744$, $\mathrm{n}=20, \mathrm{p}<0.001)$.

\section{Discussion}

Our study demonstrated that $\mathrm{BP}$ reduction elicited by the acute blockade of L-VDCC with nifedipine was always proportional to baseline BP level. This was true not only in spontaneous hypertension driven by sympathetic hyperactivity but also in angiotensin II-dependent hypertension present in homozygous Ren-2 TGR or SHR chronically treated with L-NAME. This suggests that enhanced $\mathrm{Ca}^{2+}$ influx through L-VDCC is a principal mechanism responsible for BP elevation in both forms of experimental hypertension. In all experimental groups studied the BP response to nifedipine was equal to approximately $80 \%$ of the sum of BP changes elicited by the blockade of RAS and SNS by captopril and pentolinium, respectively (Fig. 7C). It was evident that BP response to nifedipine is closely related to the degree of relative NO deficiency.
Our original hypothesis suggested that the observed nifedipine-induced BP changes reflect a part of sympathetic vasoconstriction because 1) the tonic phase of arterial contraction to $\mathrm{NE}$ is nifedipine-sensitive (Paulis et al. 2007, Líšková et al. 2007), 2) pentoliniuminduced BP fall can be attenuated by nifedipine pretreatment and vice versa (Paulis et al. 2007), and 3) $G_{i}$ protein inactivation by PTX attenuated not only BP response to endogenous or exogenous catecholamines but also nifedipine-induced BP reduction (Pintérová et al. 2010). This hypothesis was strongly supported by our results obtained in 16 experimental groups of WKY and SHR (MAP ranging from 100 to $210 \mathrm{~mm} \mathrm{Hg}$ ) without enhanced contribution of Ang II to BP maintenance. There were highly significant correlations not only between basal MAP values and MAP response to nifedipine (Fig. 7A) but also between BP responses elicited by nifedipine and those induced by pentolinium (Fig. 7B). Nevertheless, the nifedipine-sensitive BP component was always greater than the sympathetic (pentolinium-sensitive) BP component in the additional groups of rats (Ren-2 TGR and PTX-treated or L-NAMEtreated SHR), which were characterized by enhanced Ang II-dependent (captopril-sensitive) BP component. This was a reason why these additional four Ang II-dependent groups were shifted considerably to the right from the original regression line in Figure 7B (the relationship of nifedipine-sensitive BP component to sympathetic BP component), although they were close to this regression line in Figure 7A (the relationship of nifedipine-sensitive BP component to basal BP). When the relationship of nifedipine-sensitive vasoconstriction to the total vasoconstrictor activity (represented by the sum of sympathetic and Ang II-dependent BP components) was evaluated, there was a striking correlation between nifedipine-sensitive BP component and the sum of sympathetic and angiotensin II-dependent BP components in all experimental groups (Fig. 7C). Thus both sympathetic and Ang II-dependent vasoconstriction contribute to nifedipine-sensitive BP component.

The linear correlation between calcium current density in small mesenteric arteries and systolic blood pressure in SHR of different age (Lozinskaya and Cox 1997, Cox and Rusch 2002) is usually explained by the upregulation of L-VDCC in the arteries of hypertensive rats (Pratt et al. 2002, Pesic et al. 2004). The mechanism of this upregulation is still discussed. The contribution of Ang II to the upregulation of L-VDCC should be considered because the preconditioning of non- 
pressurized superior mesenteric arteries with Ang II for 24 hours increased the expression of these channels (Wang et al. 2008). Chronic Ang II effect on vascular L-VDCC upregulation was reported to be mediated by $\mathrm{Ca}_{\mathrm{V}} \beta 3$ subunit which is a critical regulatory protein required to upregulate arterial $\mathrm{Ca}_{\mathrm{V}} 1.2$ channels (Kharade et al. 2013). However, using rats with aortic ligation between renal arteries Pesic et al. (2004) reported that the expression of pore-forming $\alpha_{1 \mathrm{C}}$ subunits of these calcium channels was increased only in the right renal artery exposed to high BP but not in the left renal artery exposed to low BP, although both arteries were influenced by increased levels of circulating Ang II. This is in accordance with our observation that PTX-treated SHR had substantially decreased basal BP and reduced BP response to nifedipine even if their Ang II-dependent BP component was 10-fold increased. Nevertheless, we cannot exclude a possibility that the impact of high Ang II levels on L-VDCC might be counteracted by BP decrease occurring either below the aortic ligation (Pesic et al. 2004) or following the functional elimination of sympathetic vasoconstriction by PTX (Pintérová et al. 2010). Although our data are compatible with the idea on the upregulation of L-VDCC at high BP, we should keep in mind that the opening of these newly expressed calcium channels is clearly related to sympathetic and/or Ang II pressor activity because the functional importance of upregulated L-VDCC channels can not be demonstrated in vivo if these two pressor systems are blocked (Paulis et al. 2007). The same should also be true for the case that the abnormally enhanced $\mathrm{Ca}^{2+}$ entry through $\mathrm{Ca}_{\mathrm{V}} 1.2$ channels in genetic hypertension is due to the elevated expression of $\alpha_{2} \delta-1$ subunit responsible for augmented surface trafficking of $\mathrm{Ca}_{\mathrm{V}} 1.2$ channels (Bannister et al. 2012).

It is important to mention that the upregulation of L-VDCC after aortic ligation (Pesic et al. 2004) as well as the decrease of BP response to nifedipine after PTX (Pintérová et al. 2010) occurred within 48 h after the application of the respective stimuli, indicating that the expression of L-VDCC and their role in the control of systemic resistance might be a subject of a dynamic regulation which enables a long-term adjustment of arterial circulation to different BP levels. This can be well documented by a comparison of young and adult SHR subjected to chronic captopril treatment. The characteristic juvenile BP rise is abolished in young captopril-treated SHR but a moderate BP increase can be observed after the long-term drug withdrawal. Similar BP level (MAP around $150 \mathrm{~mm} \mathrm{Hg}$ ) can be achieved during the active captopril treatment of adult SHR with a severe established hypertension. BP responses to acute nifedipine administration were similar in both the above mentioned groups, although these young SHR never experienced such a severe hypertension as the adult ones. Thus nifedipine-sensitive BP component was always proportional to the actual BP level at the time of the experiment irrespective of the previous BP development.

Pesic et al. (2004) suggested that membrane depolarization might be a possible mechanism mediating L-VDCC upregulation at high BP because L-VDCC expression was induced by the preconditioning of renal arteries in depolarizing medium (containing $30 \mathrm{mM} \mathrm{KCl}$ ) for two days. The membrane depolarization participates not only in the myogenic response elicited by arterial distension (Brayden and Nelson 1992, Knot and Nelson 1995) but also in the vasoconstriction induced by agonist stimulation of $\mathrm{G}_{\mathrm{q} / 11}$ protein-coupled membrane receptors such as $\alpha_{1}$-adrenergic (Kazda et al. 1985) or $\mathrm{AT}_{1}$ receptors (Zhang et al. 1994). All these types of vasonstriction are sensitive to various L-VDCC blockers. Nevertheless, under the in vivo conditions it is easier to imagine that the myogenic response is a tool for tissue protection against high blood pressure or high blood flow rather than a mechanism mediating chronic BP elevation. On the other hand, membrane depolarization seems to be an integral part of sympathetic and/or Ang II-dependent vasoconstriction, namely during the tonic phase of vascular contraction. Actually there is a highly attractive concept (Gonzales et al. 2010) suggesting that increased $\mathrm{IP}_{3}$ formation (due to phospholipase $\mathrm{C}$ activation by stretch or agonists stimulating $\mathrm{G}_{\mathrm{q} / 11}$ protein-coupled receptors) leads to $\mathrm{IP}_{3}$ receptor-mediated $\mathrm{Ca}^{2+}$ release from sarcoplasmic reticulum which activates TRPM4 channels (Earley et al. 2004). TRPM4 channels together with diacyl glycerol-activated TRPC1 and TRPC6 channels permit $\mathrm{Na}^{+}$entry across plasma membrane of vascular smooth muscle cells causing thus their depolarization (Inoue et al. 2001, Poburko et al. 2007). This concept explains why each $\mathrm{IP}_{3}$-mediated phasic contraction to $\mathrm{NE}$ is followed by nifedipine-sensitive tonic contraction if $\mathrm{Ca}^{2+}$ ions are present in the incubation media (Paulis et al. 2007). It is also in line with our observation of slow and attenuated tonic contraction to $\mathrm{NE}$ in femoral arteries incubated in $\mathrm{Na}^{+}$-free media (Líšková and Zicha, unpublished data). It means that the enhanced stimulation of $\alpha_{1}$-adrenergic receptors by norepinephrine and/or $\mathrm{AT}_{1}$ receptors by angiotensin II 
causes prolonged periods of membrane depolarization which might be associated not only with augmented vasoconstriction and BP elevation but also with L-VDCC upregulation.

\section{Conclusions}

Our in vivo results elucidate the interactions of the enhanced activity of SNS and/or RAS with L-VDCC that are essential for the maintenance of elevated blood pressure in various forms of experimental hypertension. These channels seem to be upregulated by high BP and they are opened during the stimulation of blood vessels by norepinephrine and/or angiotensin II. This explains why BP response to acute nifedipine administration is always proportional not only to actual BP level but also to the sum of sympathetic and Ang II-dependent vasoconstriction. The down-regulation of nifedipinesensitive mechanisms during different forms of chronic antihypertensive therapy helps to understand why so many different antihypertensive drugs can be used for hypertension treatment.

\section{Conflict of Interest}

There is no conflict of interest.

\section{Acknowledgements}

This work was supported by grants AV0Z 50110509, $1 \mathrm{M} 0510$ (Ministry of Education of the Czech Republic), 305/09/0336 and 304/12/0259 (Czech Science Foundation).

\begin{abstract}
Abbreviations
Ang II, angiotensin II; AT1, angiotensin Type 1; BP, blood pressure; HanSD, Hannover, Sprague Dawley;

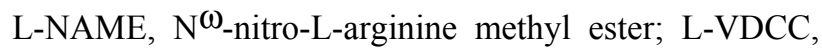
L-type voltage-dependent calcium channel; MAP, mean arterial pressure; NE, norepinephrine; NO, nitric oxide; NOS, NO synthase; PE, polyethylene; PTX, pertussis toxin; RAS, renin-angiotensin system; SHR, spontaneously hypertensive rats; SNS, sympathetic nervous system; TGR, transgenic rats; TRPC, transient receptor potential cation channel subfamily C; TRPM, transient receptor potential cation channel subfamily $\mathrm{M}$; WKY, Wistar-Kyoto rats.
\end{abstract}

\section{References}

BADER M, ZHAO Y, SANDER M, LEE MA, BACHMANN J, BÖHM M, DJAVIDANI B, PETERS J, MULLINS JJ, GANTEN D: (1992) Role of tissue renin in the pathophysiology of hypertension in TGR(mREN2)27 rats. Hypertension 19: 681-686.

BANNISTER JP, BULLEY S, NARAYANAN D, THOMAS-GATEWOOD C, LUZNY P, PACHUAU J, JAGGAR $\mathrm{JH}$ : Transcriptional upregulation of $\alpha_{2} \delta-1$ elevates arterial smooth muscle cell voltage-dependent $\mathrm{Ca}^{2+}$ channel surface expression and cerebrovascular constriction in genetic hypertension. Hypertension 60: 1006-1015, 2012.

BERECEK KH, KIRK KA, NAGAHAMA S, OPARIL S: Sympathetic function in spontaneously hypertensive rats after chronic administration of captopril. Am J Physiol 252: H796-H806, 1987.

BISHOP JE, KIERNAN LA, MONTGOMERY HE, GOHLKE P, MCEWAN JR: (2000) Raised blood pressure, not renin-angiotensin systems, causes cardiac fibrosis in TGR m(Ren2)27 rats. Cardiovasc. Res. 47, 57-67.

BÖHM M, ZOLK O, FLESCH M, SCHIFFER F, SCHNABEL P, STASCH JP, KNORR A: (1998) Effects of angiotensin II type 1 receptor blockade and angiotensin-converting enzyme inhibition on cardiac betaadrenergic signal transduction. Hypertension 31: 747-754.

BRAYDEN JE, NELSON MT: Regulation of arterial tone by activation of calcium-dependent potassium channels. Science 256: 532-535, 1992.

COX RH, RUSCH NJ: New expression profiles of voltage-gated ion channels in arteries exposed to high blood pressure. Microcirculation 9: 243-257, 2002.

DE CHAMPLAIN J: Pre- and postsynaptic adrenergic dysfunctions in hypertension. J Hypertens 8 (Suppl 7): S77-S85, 1990.

DOBEŠOVÁ Z, KUNEŠ J, ZICHA J: The altered balance between sympathetic nervous system and nitric oxide in salt hypertensive Dahl rats: ontogenetic and $F_{2}$ hybrid studies. J Hypertens 20: 945-955, 2002.

EARLEY S, WALDRON BJ, BRAYDEN JE: Critical role for transient receptor potential channel TRPM4 in myogenic constriction of cerebral arteries. Circ Res 95: 922-929, 2004. 
GODFRAIND T, KAZDA S, WIBO M: Effects of a chronic treatment by nisoldipine, a calcium antagonistic dihydropyridine, on arteries of spontaneously hypertensive rats. Circ Res 68: 674-682, 1991.

GONZALES AL, AMBERG GC, EARLEY S: $\mathrm{Ca}^{2+}$ release from the sarcoplasmic reticulum is required for sustained TRPM4 activity in cerebral artery smooth muscle cells. Am J Physiol Cell Physiol 299: C279-C288, 2010.

HEAD RJ: Hypernoradrenergic innervation: its relationship to functional and hyperplastic changes in the vasculature of the spontaneously hypertensive rat. Blood Vessels 26: 1-20, 1989.

HERMSMEYER K: Differences of calcium channels in vascular muscle in hypertension. Am J Hypertens 4: 412S415S, 1991.

HIRTH-DIETRICH C, STASCH JP, GANTEN D, LUFT FC: (1994) Renal effects of captopril and nitrendipine in transgenic rats with an extra renin gene. Hypertension 23: 626-631.

HOJNÁ S, KADLECOVÁ M, DOBEŠOVÁ Z, VALOUŠKOVÁ V, ZICHA J, KUNEŠ J: (2007) The participation of brain NO synthase in blood pressure control of adult spontaneously hypertensive rats. Mol. Cell. Biochem. 297: 21-29.

INOUE R, OKADA T, ONOUE H, HARA Y, SHIMIZU S, NAITOH S, ITO Y, MORI Y: The transient receptor potential protein homologue TRP6 is the essential component of vascular alpha ${ }_{1}$-adrenoceptor-activated $\mathrm{Ca}^{2+}$ permeable cation channel. Circ Res 88: 325-332, 2001.

ISHIKAWA T, HUME JR, KEEF KD: Regulation of $\mathrm{Ca}^{2+}$ channels by cAMP and cGMP in vascular smooth muscle cells. Circ Res 73: 1128-1137, 1993.

KAZDA S, GARTHOFF B, KNORR A: Interference of calcium antagonist nisoldipine with the abnormal response of vessels from hypertensive rats to alpha-adrenergic stimulation. J Cardiovasc Pharmacol 7 (Suppl 6): S61-S65, 1985.

KHARADE SV, SONKUSARE SK, SRIVASTAVA AK, THAKALI KM, FLETCHER TW, RHEE SW, RUSCH NJ: The $\beta 3$ subunit contributes to vascular calcium channel upregulation and hypertension in angiotensin II-infused C57BL/6 mice. Hypertension 61: 137-142, 2013.

KNOT HJ, NELSON MT: Regulation of membrane potential and diameter by voltage-dependent $\mathrm{K}^{+}$channels in rabbit myogenic cerebral arteries. Am J Physiol 269: H348-H355, 1995.

KUNEŠ J, DOBEŠOVÁ Z, ZICHA J: Altered balance of main vasopressor and vasodepressor systems in rats with genetic hypertension and hypertriglyceridaemia. Clin Sci 102: 269-277, 2002.

KUNEŠ J, HOJNÁ S, KADLECOVÁ M, DOBEŠOVÁ Z, RAUCHOVÁ H, VOKURKOVÁ M, LOUKOTOVÁ J, PECHÁŇOVÁ O, ZICHA J: (2004) Altered balance of vasoactive systems in experimental hypertension: the role of relative NO deficiency. Physiol. Res. 53 (Suppl. 1): S23-S34.

LEWIS SJ, BHOPATKAR MY, WALTON TM, BATES JN: Role of voltage-sensitive calcium-channels in nitric oxide-mediated vasodilation in spontaneously hypertensive rats. Eur J Pharmacol 528: 144-149, 2005.

LÍŠKOVÁ S, KUNEŠ J, ZICHA J: Nifedipine-sensitive vascular reactivity of femoral arteries in WKY: the effects of pertussis toxin pretreatment and endothelium removal. Physiol Res 56: 663-666, 2007.

LIU H, XIONG Z, SPERELAKIS N: Cyclic nucleotides regulate the activity of L-type calcium channels in smooth muscle cells from rat portal vein. J Mol Cell Cardiol 29: 1411-1421, 1997.

LOZINSKAYA IM, COX RH: Effects of age on $\mathrm{Ca}^{2+}$ currents in small mesenteric artery myocytes from Wistar-Kyoto and spontaneously hypertensive rats. Hypertension 29: 1329-1336, 1997.

NARITA H, NAGAO T, YABANA H, YAMAGUCHI I: (1983) Hypotensive and diuretic actions of diltiazem in spontaneously hypertensive and Wistar Kyoto rats. J. Pharmacol. Exp. Ther. 227: 472-477.

NELSON MT, STANDEN MB, BRAYDEN JE, WORLEY JF: Noradrenaline contracts arteries by activating voltagedependent calcium channels. Nature 336: 382-385, 1988.

OHYA Y, TSUCHIHASHI T, KAGIYAMA S, ABE I, FUJISHIMA M: Single L-type calcium channels in smooth muscle cells from resistance arteries of spontaneously hypertensive rats. Hypertension 31: 1125-1129, 1998.

ORLOV SN, TREMBLAY J, HAMET P: cAMP signaling inhibits dihydropyridine-sensitive $\mathrm{Ca}^{2+}$ influx in vascular smooth muscle cells. Hypertension 27: 774-780, 1996.

PARK JK, FIEBELER A, MULLER DN, MERVAALA EM, DECHEND R, ABOU-REBYEH F, LUFT FC, HALLER $\mathrm{H}$ : (2002) Lacidipine inhibits adhesion molecule and oxidase expression independent of blood pressure reduction in angiotensin-induced vascular injury. Hypertension 39: 685-689. 
PAULIS L, LÍŠKOVÁ S, PINTÉROVÁ M, DOBEŠOVÁ Z, KUNEŠ J, ZICHA J: Nifedipine-sensitive noradrenergic vasoconstriction is enhanced in spontaneously hypertensive rats: the influence of chronic captopril treatment. Acta Physiol (Oxford) 191: 255-266, 2007.

PECHÁŇOVÁ O, DOBEŠOVÁ Z, ČEJKA J, KUNEŠ J, ZICHA J: Vasoactive systems in L-NAME hypertension: the role of inducible NO synthase. J Hypertens 22: 167-173, 2004.

PESIC A, MADDEN JA, PESIC M RUSCH NJ: High blood pressure upregulates arterial L-type $\mathrm{Ca}^{2+}$ channels: is membrane depolarization the signal? Circ Res 94: e97-e104, 2004.

PINTÉROVÁ M, LÍŠKOVÁ S, DOBEŠOVÁ Z, BEHULIAK M, KUNEŠ J, ZICHA J: Impaired control of L-type voltage-dependent calcium channels in experimental hypertension. Physiol Res 58 (Suppl 2): S43-S54, 2009.

PINTÉROVÁ M, KAREN P, KUNEŠ J, ZICHA J: Role of nifedipine-sensitive sympathetic vasoconstriction in maintenance of high blood pressure in spontaneously hypertensive rats: effect of $\mathrm{G}_{\mathrm{i}}$-protein inactivation by pertussis toxin. $J$ Hypertens 28: 969-978, 2010.

PINTÉROVÁ M, KUNEŠ J, ZICHA J: Altered neural and vascular mechanisms in hypertension. Physiol Res 60: 381402, 2011.

POBURKO D, LIAO CH, LEMOS VS, LIN E, MARUYAMA Y, COLE WC, VAN BREEMEN C: Transient receptor potential channel 6-mediated, localized cytosolic $\left[\mathrm{Na}^{+}\right]$transients drive $\mathrm{Na}^{+} / \mathrm{Ca}^{2+}$ exchanger mediated $\mathrm{Ca}$ entry in purinergically stimulated aorta smooth muscle cells. Circ Res 101: 1030-1038, 2007.

PRATT PF, BONNET S, LUDWIG LM, BONNET P, RUSCH NJ: Upregulation of L-type $\mathrm{Ca}^{2+}$ channels in mesenteric and skeletal arteries of SHR. Hypertension 40: 214-219, 2002.

SHARMA JN, FERNANDEZ PG, LAHER I, TRIGGLE CR: (1984) Differential sensitivity of Dahl salt-sensitive and Dahl salt-resistant rats to the hypotensive action of acute nifedipine administration. Can. J. Physiol. Pharmacol. 62: 241-243.

SONKUSARE S, PALADE PT, MARSH JD, TELEMAQUE S, PESIC A, RUSCH NJ: Vascular calcium channels and high blood pressure. pathophysiology and therapeutic implications. Vascul Pharmacol 44: 131-142, 2006.

TAKATA Y, HUTCHINSON JS: (1983) Exaggerated hypotensive responses to calcium antagonists in spontaneously hypertensive rats. Clin. Exp. Hypertens. A 5: 827-847.

VANĚČKOVÁ I, DOBEŠOVÁ Z, KUNEŠ J, ZICHA J: (2012) The effects of repeated delivery of angiotensin II $\mathrm{AT}_{1}$ receptor antisense on distinct vasoactive systems in Ren-2 transgenic rats: young vs. adult animals. Hypertens. Res. 35: 761-758.

WANG WZ, PANG L, PALADE P: Angiotensin II causes endothelial-dependent increase in expression of $\mathrm{Ca}_{\mathrm{V}} 1.2$ protein in cultured arteries. Eur J Pharmacol 599: 117-120, 2008.

WITTE K, HUSER L, KNOTTER B, HECKMANN M, SCHIFFER S, LEMMER B: (2001) Normalisation of blood pressure in hypertensive TGR(mREN2)27 rats by amlodipine vs. enalapril: effects on cardiac hypertrophy and signal transduction pathways. Naunyn-Schmiedebergs Arch. Pharmacol. 363: 101-109.

ZHANG JS, VAN MEEL JC, PFAFFENDORF M, ZHANG J, VAN ZWIETEN PA: Calcium dependency of the AT ${ }^{-}$ receptor mediated effects in the rat portal vein: influence of calcium antagonists. Naunyn-Schmiedebergs Arch Pharmacol 349: 437-442, 1994.

ZICHA J, DOBEŠOVÁ Z, KUNEŠ J: Relative deficiency of nitric oxide-dependent vasodilation in salt hypertensive Dahl rats: the possible role of superoxide anions. J Hypertens 19: 247-254, 2001.

ZICHA J, DOBEŠOVÁ Z, KUNEŠ J: Antihypertensive mechanisms of chronic captopril or N-acetylcysteine treatment in L-NAME hypertensive rats. Hypertens Res 29: 1021-1027, 2006.

ZICHA J, DOBEŠOVÁ Z, PINTÉROVÁ M, BEHULIAK M, KUNEŠ J: Quite different role of renin-angiotensin system (RAS) and sympathetic nervous system (SNS) in blood pressure (BP) regulation in chronically NOdeficient SHR or Wistar rats. J Hypertens 27 (Suppl 2): S299, 2009.

ZICHA J, DOBEŠOVÁ Z, BEHULIAK M, KUNEŠ J, VANĚČKOVÁ I: Preventive dietary potassium supplementation in young salt-sensitive Dahl rats attenuates development of salt hypertension by decreasing sympathetic vasoconstriction. Acta Physiol (Oxf) 202: 29-38, 2011. 